\title{
ELEVAÇÃO (ERHÖRUNG) E CULTIVO (ZÜCHTUNG) NA FILOSOFIA DE NIETZSCHE
}

\author{
ELEVATION (ERHÖRUNG) AND BREEDING (ZÜCHTUNG) IN \\ NIETZSCHE'S PHILOSOPHY
}

\section{ILDENILSON MEIRELES}

( Universidade Estadual de Montes Claros, Brasil)

\begin{abstract}
RESUMO
O artigo apresenta as variáveis de uma noção cara à filosofia nietzschiana, a noção de cultivo ou seleção (Züchtung), articulada ao projeto mais geral de elevação do homem. Consideramos que essa noção é de importância capital para uma compreensão do pensamento de Nietzsche sobre a cultura superior, principalmente pelo aspecto mais propositivo que ela alcança nos últimos escritos. A partir disso, a hipótese a ser desenvolvida é de que o constante uso dessa noção nos últimos escritos abre a possibilidade de considerar uma mudança substancial no pensamento de Nietzsche sobre a cultura, não mais como tarefa histórico-universal, mas como tarefa voltada exclusivamente aos indivíduos de exceção.
\end{abstract}

Palavras-chave: Cultivo. Cultura. Moral. Indivíduos de exceção.

\begin{abstract}
The article presents the variables of a valuable notion for Nietzschean philosophy, the notion of breeding or selection (Züchtung), articulated to the more general project of man's elevation. We consider that this notion has essential importance for an understanding of Nietzsche's thought about the superior culture, mainly by the more propositional aspect it reaches in the last writings. From this, the hypothesis to be developed is that the constant use of this notion in recent writings opens the possibility to consider a substantial change in Nietzsche's thought about the culture, no longer as a historical-universal task, but as a task dedicated exclusively to the exceptional men.
\end{abstract}

Keywords: Breeding. Culture. Morality. Exceptional men.

\section{Introdução}

Em Ecce Homo, numa referência às Considerações Extemporâneas, Nietzsche faz a seguinte afirmação: "No fundo, com esses escritos eu desejava fazer algo bem diferente de psicologia - um problema de educação sem equivalente, um novo conceito de cultivo de si (Selbst-Zucht), defesa de si (Selbst-Vertheidigung) até a dureza, um caminho para a grandeza e

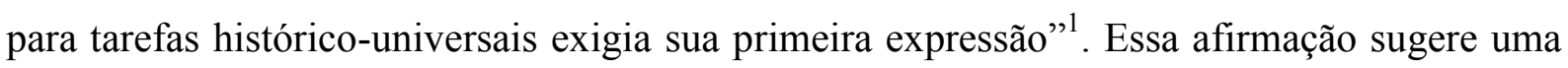
pista importante para o desenvolvimento da nossa questão, a saber, o fato de que as preocupações de Nietzsche com a elevação do homem e o ideal de uma cultura superior, preocupações bastante acentuadas nos textos de 1886 e 87, se articulam diretamente com suas expectativas em relação ao grande homem e à cultura elevada desde os textos de juventude ${ }^{2}$. 
O Nascimento da tragédia (1871) e as Considerações Extemporâneas (1873/75), por exemplo, tomam a elevação da cultura como fio condutor do empreendimento críticofilosófico de Nietzsche, certamente balizada pela "verdadeira formação" (Bildung) em contraposição ao destino da formação definida pelo Estado. Se na primeira obra publicada o vetor é a arte trágica como expressão de uma cultura superior e a defesa da música de Wagner realiza aí a tarefa da arte suprema da vida; as Considerações Extemporâneas confirmam essas expectativas de Nietzsche na medida e que fornecem um diagnóstico preciso da modernidade cultural da Alemanha tomando por base a completa dispersão dos objetivos da cultura, a ausência de um estilo próprio ao "espírito alemão" e a supervalorização da formação (Bildung) no sentido da instrução (Gelehtheit) em detrimento da verdadeira formação que deveria operar como meio para se alcançar uma cultura superior. A noção de formação assumida por Nietzsche nas Extemporâneas toma partido da Bildung como instância indispensável no horizonte de uma cultura superior que ainda precisa ser conquistada em benefício das condições de surgimento do gênio. Sob esse aspecto, Nietzsche toma para si dois exemplos muito claros a partir dos quais se pode articular, nesse momento, formação no sentido de "elevação" das condições individuais -, e cultura superior: Schopenhauer como modelo de educador e Wagner como modelo de gênio.

Se nesse primeiro registro citado acima se desenvolve a noção nietzschiana de Cultura correlacionada à ideia de Bildung, a partir de Humano, demasiado Humano (1878), que se poderia considerar um segundo registro, as expectativas em relação a uma "höhere Cultur" aparecem com bastante frequência, por exemplo, quando se constata a presença do termo nos $\S \S 252,275,281,285$ e 439, quase sempre contraposto a uma cultura inferior. Esses dois registros permitem encaminhar nossa questão no seguinte sentido: se é verdade que há uma aposta de Nietzsche num processo de educação (Erziehung) capaz de orientar o indivíduo para uma cultura superior, na contramão do modo como a educação e os processos de formação se estabeleceram no interior da cultura de sua época, não é menos verdade que ele mantém seu pensamento acerca de uma cultura superior, balizado, desta feita, não mais pela noção de educação, mas pelas noções de seleção e cultivo (Züchtung). É o que se pode ver, por exemplo, no contexto de Além de Bem e Mal, quando Nietzsche se refere "ao filósofo tal como nós o entendemos, nós, espíritos livres - como o homem da responsabilidade mais ampla, que se preocupa com a evolução total do homem"3. Sob esse signo da responsabilidade com a "evolução total do homem", ainda na mesma passagem, "esse filósofo", como Nietzsche o concebe, "se utilizará das religiões para a sua obra de educação e cultivo, do 
mesmo modo que se utilizará das condições políticas e econômicas do momento".

Entretanto, queremos argumentar a favor da ideia de que Nietzsche abandona, nos textos de 1888, sua grande expectativa de que a "cultura superior" pudesse se efetivar a partir de uma reformulação no interior das instâncias da cultura vigente e começa a fazer sua aposta mais decisiva na elevação do tipo homem orientada pela noção de cultivo de si. Trata-se, a nosso ver, de uma mudança de perspectiva que, se não indica um completo desinteresse de Nietzsche por grandes empreendimentos da cultura, pelo menos freia seu entusiasmo e coloca em cena o privilégio dos indivíduos de exceção (Ausnahme-Menschen), que já figuram no $\S$ 169 de Opiniões e Sentença ${ }^{4}$ e que se caracterizam, a partir daí, como aqueles unicamente capazes de impor a si mesmos e a partir de si mesmos um novo critério de seleção e cultivo. Levando em consideração as variações da noção de Züchtung nas obras publicadas a partir de Além de Bem e Mal e nos fragmentos póstumos ${ }^{5}$, seus vários sentidos podem ser articulados com o tema da elevação (Erhörung), por exemplo, no sentido da cultura, da moral e do indivíduo. Tendo em vista uma melhor delimitação da noção de cultivo para o uso que Nietzsche fará dela nos textos a partir de 1886, esboçaremos a seguir uma distinção entre essa noção de cultivo e noções próximas para, a partir daí, alcançarmos uma compreensão mais clara do cultivo de si como uma nova aposta no futuro do homem e no destino da cultura.

\section{Sentido geral de Züchtung}

Cultivar (züchten) tem vários sentidos muito próximos: i) criar, no sentido de criação de animais; ii) no sentido botânico, de cultivo de espécies de plantas; iii) no sentido biológico, de seleção ou cultivo de células e tecidos para fins de reprodução em escala serial; iv) no sentido jurídico de impor disciplina, castigar, corrigir etc., como bem mostrou Wilson Frezzatti ${ }^{6}$ numa nota que acompanha sua tradução dos fragmentos póstumos de Nietzsche sobre Darwin. Nesses domínios, o cultivo está basicamente orientado pela possibilidade de "melhoramento" ou "regeneração" de tipos e espécies de objetos, nos casos da botânica e da biologia, e do comportamento no caso jurídico. Sabe-se, pelos fragmentos póstumos e alguns trechos de obras publicadas, que o debate mais fecundo de Nietzsche acerca desse tema é com as ciências da natureza, mais precisamente com algumas teorias biológicas correntes no século $\mathrm{IX}^{7}$, especialmente as darwinistas. Nesse sentido, Darwin parece ser o grande objeto de contestação por parte do filósofo alemão na medida em que sua teoria da seleção natural (natürlich Selektion) privilegia justamente as noções de adaptação (Anpassung), conservação (Erhaltung) e, em sentido moral, a noção de domesticação (Zähmung). O aspecto mais 
fundamental no entorno dessa noção naturalista de seleção ou cultivo (Züchtung) é que ela quase sempre se aplica ao melhoramento da espécie, sua preservação e continuidade na existência ao modo de uma multiplicação dos tipos naturalmente selecionados pelas condições do meio, dentre outros aspectos. A implicação mobilizada por essa concepção é que ela, uma vez transposta para o âmbito da cultura, torna o tipo de homem que daí resulta o tipo superior na medida em que conseguiu perseverar na existência graças à capacidade de adaptação na luta pela vida. É desse lugar das preocupações culturais que a crítica de Nietzsche parece fornecer seu tom mais corrosivo na denúncia de que os ideais da cultura, ao contrário do que celebram os partidários do progresso do animal-homem, os "melhoradores da humanidade", encontram eco no enfraquecimento cada vez mais acentuado do tipo homem perpetrado por uma forma bem peculiar de "cultivo", a domesticação (Zähmung). Essa percepção de Nietzsche é alimentada pelo reconhecimento de que o tipo humano superior perpetrado pela cultura 'seletiva' (Züchtung) da modernidade é o "homem bom", o “cristão". Esse tipo, "o homem bom' como sintoma de esgotamento", europeia pode ser referido à figura do último homem, aquele "que tem vida mais longa", conforme explicitado por Zaratustra. Daí se pode deduzir, por um lado, que esse tipo de homem chancelado como ideal da modernidade cumpre rigorosamente o programa de uma moral seletiva (Züchtung) cuja tendência é fortemente marcada mais pela domesticação (Zähmung) do que propriamente pela elevação do tipo homem. Trata-se, nesses termos, menos de disciplina e cultivo de virtudes que conduzam o homem à autossuperação do que de amansamento do animal-homem, de enfraquecimento e esgotamento de suas forças para fins de utilidade. Ancorada nesse tipo domesticado e enfraquecido como sua meta, a cultura vive, agora, à custa da sua descendência também como forma de autopreservação (Selbsterhaltung).

\section{Os vários sentidos de Züchtung na obra de Nietzsche}

O primeiro indício de que a noção de cultivo em Nietzsche ganha um contorno sui generis é o fato de que ela não se presta a endossar o modus operandi da cultura vigente nem os ideais pretendidos por ela. Uma aposta inicial disso pode ser a fecunda análise que ele realiza em suas Considerações Extemporâneas, apesar de o termo não ser usado por Nietzsche nesse texto. Elaborados entre 1873/76, os textos das Considerações Extemporâneas esboçam com bastante acidez a crítica de Nietzsche à cultura vigente em sua época, ao tipo de homem formado sob a égide da educação erudita, às instituições que fornecem um programa 
de ensino (Erziehung) mais voltado para a instrução (Belehrtheit) técnica da "massa" do que para a formação (Bildung) e cultivo dos grandes homens. Nessa época, envolvido ainda com as expectativas de uma reforma radical dos meios de produção da cultura, o filósofo se manifesta em favor de uma cultura superior capaz de produzir o grande homem, o gênio ${ }^{10}$, e elevar-se para além dos ideais políticos que sustentam a cultura vigente. Essa segunda intervenção de Nietzsche em defesa de uma cultura superior ou elevada - a primeira talvez seja o projeto de $O$ Nascimento da tragédia - torna manifesta sua expectativa positiva em relação às transformações pelas quais precisam passar os estabelecimentos de ensino, bem como as instituições em geral, no sentido de deslocar o sentido cultural da educação de uma atividade imediatista para um processo lento de formação e cultivo. $O$ diagnóstico apresentado por Nietzsche nas Considerações Extemporâneas, malgrado a inexistência do termo "cultivo" nesse texto, apresenta justamente um tipo de homem no qual falta a disciplina necessária que prepararia o caminho ao grande homem, aquele indivíduo de exceção que levaria a cultura continuamente ao ápice de suas mais altas potencialidades e produziria, no final do ciclo, uma renovação da mesma. Em suma, no âmbito das preocupações culturais de Nietzsche, nesse momento, acentua-se a ideia segundo a qual as virtudes mais elevadas devem ser transmitidas pela educação, perspectiva que se contrapõe radicalmente ao programa educacional de sua época balizado pela instrução, pelo imediatismo e pela ausência de unidade nos propósitos da cultura.

Um segundo indício de que o cultivo, em sentido nietzschiano, está muito distante daquele praticado em sua época é o modo como se expressa num fragmento póstumo de Maio/Junho de 1885, quando diz acerca da moral: "Toda moral foi, até agora, antes de tudo, a expressão de uma vontade conservadora voltada para o cultivo de uma mesma espécie, com o imperativo: 'é necessário prevenir toda variação; deve restar somente o prazer de usufruir de tal espécie'. Aqui, um grande número de propriedades se mantém conservada e altamente cultivada, e outras sacrificadas" $" 1$. Isso pode se articular com uma passagem de Assim falou Zaratustra que destaca o tipo de homem vigente no qual a modernidade deposita todos os seus esforços e do qual emana a figura do último homem. Ora, Zaratustra fala justamente de um tipo que representa o declínio do homem, malgrado a moral ordinária compreender esse tipo como progresso e melhoramento do homem em função de todo o investimento de longa duração que realizou sobre ele. Não se pode negligenciar o fato de que ainda nesse texto Nietzsche alimenta expectativas positivas em relação à superação do homem, o que pode ser atestado pela introdução do seu contra-ideal, o Übermensch. Nesses termos, sua aposta mais arrojada se inscreve no programa de elevação do homem a partir de um novo quadro de 
virtudes promissoras de uma superação do homem. Ainda nesse mesmo sentido, se relacionarmos Assim falou Zaratustra com Aurora, textos preparados no mesmo conjunto das "reflexões sobre os pensamentos morais", o que aparece não é outra coisa senão a tentativa de Nietzsche em pensar a moral como meio de cultivo do tipo homem. Ou seja, a tarefa da cultura na preparação do advento do além-do-homem é uma tarefa eminentemente moral. É essa ideia da moral como meio de formação e cultivo que figura no aforismo 9 de Aurora e que traz o título "Conceito da moralidade do costume". A força da tradição no cultivo do indivíduo exige a pujança do "círculo da moralidade"", algo que Nietzsche vê se perder na moral moderna em virtude da prerrogativa do indivíduo em relação à comunidade. É essa relação comunidade/indivíduo, esse vínculo que prende o indivíduo à comunidade por meio de uma rígida formação e disciplina, próprias à moralidade do costume, que alimenta a possibilidade da auto-superação do indivíduo, mas em benefício das virtudes da comunidade: “A auto-superação é exigida não por suas consequências úteis para o indivíduo, mas a fim de que o costume, a tradição apareça vigorando, não obstante toda vantagem e desejo individual: o indivíduo deve (soll) sacrificar-se - assim reza a moralidade do costume" ${ }^{\not 1}$. O resultado esperado pelo círculo da moralidade do costume é, pois, a elevação do indivíduo ao nível da autonomia moral. Os efeitos desse "círculo da moralidade" como meio de cultivo do homem aparecem na medida em que, segundo o filósofo, “quem quisesse erguer-se acima dele tinha que se tornar legislador e curandeiro, e uma espécie de semideus: isto é, tinha de criar costumes - algo terrível, mortalmente perigoso!"14.

Por fim, um terceiro indício que gostaríamos de perseguir acerca da noção nietzscheana de cultivo se articula diretamente com a concepção de que a moral pode ser tomada como meio de formação e elevação da cultura. É aqui que entendemos haver uma proximidade entre cultura seletiva e círculo da moralidade dos costumes, tomado, também, no sentido do cultivo de determinadas virtudes. Sob esse aspecto, arriscamos a hipótese de que as análises de Nietzsche sobre a moral, até Genealogia da Moral, tem como pano de fundo suas preocupações com o aspecto mais geral da cultura na medida em que sua crítica do homem moderno, o enfraquecimento do animal-homem, deixa transparecer a décadence cultural que ganhou ascendência na modernidade por meio das morais do ressentimento e da compaixão. Ressentimento e compaixão parecem ser os dois grandes movimentos com os quais Nietzsche tem de se debater intensamente tanto no sentido de formular as condições históricas de suas gêneses, portanto de fazer suas genealogias, quanto de ensaiar alternativas possíveis de impor um novo sentido da cultura (a cultura elevada ou superior), uma nova meta para o tipo homem 
(o Übermensch ou indivíduo soberano), uma nova moral (a dos filósofos legisladores). Do ponto de vista do problema, o alcance da moral do ressentimento e da compaixão no encaminhamento das questões humanas parece a Nietzsche comprometer o futuro do homem na medida em que ambas as instâncias, ressentimento e compaixão, cumprem o papel decisivo e eficaz de enfraquecimento do animal-homem, o que certamente inviabiliza a elevação do homem ao além-do-homem, bem como mantém a cultura num estágio de estagnação, o que certamente compromete o seu ciclo vital e a torna infértil em relação a novas possibilidades de seleção e cultivo.

\section{Cultivo de si como autoformação}

Se até 1887 Nietzsche tem expectativas de reformular o sentido da cultura apostando no além-do-homem como ideal de um tipo superior e redentor que "nos salvará não só do ideal vigente, como daquilo que dele forçosamente nasceria, do grande nojo, da vontade de nada, do niilismo" "15, a partir daí, nos textos subsequentes, observa-se uma mudança significativa nessas expectativas depositadas nesse "homem redentor" e a elevação do homem passa a ser creditada na economia de um cultivo de si. Doravante, parece tratar-se de uma perspectiva que volta sua atenção ao modo como o "indivíduo", a partir de si mesmo, é capaz de arregimentar determinadas virtudes e empreender em si um processo de auto-formação. Não se trata mais de esperar pelo Übermensch anunciado por Zaratustra, nem pelo "homem redentor" esboçado em Genealogia da Moral. Para Nietzsche, nesse momento, trata-se da tarefa de tornar-se si mesmo, de devolver ao indivíduo a prerrogativa de cuidar de si, autoformar-se, cultivar a si mesmo como forma de autoelevação para além da moral gregária e das ideias modernas. Na medida em que desaparecem quase que completamente nos textos de 1888 a figura do além-do-homem, as análises sobre o ressentimento e a compaixão; e a expectativa de uma cultura elevada parece dar lugar aos homens de exceção (AusnahmeMenschen), somos levados a pensar o individuum ${ }^{16}$ como lugar privilegiado do cultivo das virtudes nobres ${ }^{17}$. Isso parece se confirmar pelo fato de Nietzsche manter, com mais precisão e de modo mais orientado, as noções de cultivo e seleção (Züchtung), disciplina (Zucht) e formação (Bildung) não em relação à cultura em geral ou ao "povo", mas em relação aos indivíduos de exceção. Ecce Homo (1888) representa, a nosso ver, o grande empreendimento em relação ao homem cultivado, talvez a mudança mais significativa no intento de pensar a elevação do homem, na medida em que nele Nietzsche adota uma estratégia argumentativa que não parece mais simplesmente esboçar uma superação do homem, idealizar e exigir o 
advento do além-do-homem como forma de redenção do homem, nem mesmo continuar sua luta contra a moral do ressentimento. Ao contrário disso, Ecce Homo traz a marca da afirmação incondicional de tudo aquilo que foi a "vida" de Nietzsche, além de ser uma espécie de prognóstico para novas virtudes, aquelas que doravante pertencem ao caráter seletivo dos indivíduos de exceção e somente por eles podem ser cultivadas, acumuladas e tornadas produtivas na dinâmica da autossuperação.

É certo que ao retomar suas obras, mesmo de modo bastante resumido, Nietzsche pretende não só fazer um balanço geral de seu pensamento, mas derivar de suas obras os aspectos fundamentais que teriam alcançado termo no amor fati, expresso justamente em Ecce Homo; e na transvaloração dos valores, confirmada por $O$ Anticristo. No primeiro caso, parece-nos que uma primeira pista acerca disso é fornecida pela ideia mesma de elaboração de um livro em que Nietzsche diz contar a si mesmo sua própria vida. Com isso, Ecce Homo sinaliza a entrada em cena de um tipo, o tipo-Nietzsche-psicólogo que apresenta, ao final de um longo processo de experimentação nas mais diversas perspectivas morais, sua autocompreensão, sua psicologia sem igual acerca de si mesmo. Todo o seu esforço argumentativo busca convencer o leitor sobre o modo como sua perambulação pelas várias morais e sua frequentação no movimento da décadence demonstraram, no fim das contas, que a afirmação incondicional do mundo e da vida é prerrogativa dos indivíduos de exceção. Nesse caso, Nietzsche seria, ele mesmo, um indivíduo no qual o cultivo de determinadas virtudes assegurou sua auto-elevação como tipo-homem e permitiu a formação de sua própria Personlichkeit.

No segundo caso, parece importante aproximar as questões expostas em Genealogia da Moral com aquelas expostas na obra que compunha o projeto de Nietzsche de escrever sua Umwerthung aller Werthe, O Anticristo. Nesse livro preparado por Nietzsche para publicação, arauto da crítica mais virulenta aos ideais do cristianismo, Nietzsche contrapõe ao homem fraco da moral cristã, ao homem moderno, a promessa de um tipo mais elevado. Para ele, não se trata de saber "o que sucederá à humanidade na sequência dos seres (- o homem é um fim), mas que tipo de homem deve-se cultivar, deve-se querer como de mais alto valor, mais digno de vida, mais certo de futuro" ${ }^{18}$. A expectativa de Nietzsche em $O$ Anticristo se justifica em função tanto da compreensão de que a elevação do homem não requer a lógica do "progresso" da humanidade celebrado pelas ideias modernas: "O europeu de hoje permanece, em seu valor, muito abaixo do menos europeu da Renascença; mais desenvolvimento não significa absolutamente, por alguma necessidade elevação (Erhöhung), aumento (Steigerung), 
fortalecimento (Verstärkung)"," um contínuo êxito de casos particulares, nos mais diversos lugares da Terra e nas mais diversas culturas, nos quais um tipo mais elevado (ein höherer Typus) realmente se manifesta" ${ }^{20}$. Além dessa expectativa, Nietzsche, em $O$ Anticristo, considera ter alcançado o ponto máximo do seu projeto: "nós próprios, nós, espíritos livres, somos já uma 'transvaloração de todos os valores' (wir selbst, wir freien Geister, sind bereits eine 'Umwerthung aller Werthe",21. Isso é um indicativo de que a crítica nietzscheana do cristianismo levada a efeito nessa obra tem como escopo principal, além de exaltar certas conquistadas da sua filosofia prometidas pelas análises anteriores, reafirmar a necessidade de combater os tipos psicológicos representantes dos mais altos ideais da décadence.

\section{Conclusão}

A partir da análise precedente, não é sem fundamento defender a ideia de que um dos alcances mais significativos da filosofia de Nietzsche, na medida em que destaca determinadas virtudes a partir das quais se pode pretender uma auto-elevação do homem, está justamente no plano do cultivo das virtudes morais direcionadas não para o sentido geral da cultura, em primeiro plano, mas para o indivíduo. Ou seja, Nietzsche parece inverter a perspectiva que tinha assumido desde Aurora quando considerava que o meio para se alcançar uma cultura elevada se daria na formação do indivíduo no interior de um círculo da moralidade, a exemplo da moralidade dos costumes da tradição, e sinaliza agora, nos textos de 1888, para a contínua auto-elevação do homem por meio do cultivo de virtudes morais destinadas unicamente aos indivíduos de exceção. Se ainda persiste a moral como meio de formação e cultivo, ela não se orienta para a planificação do tipo elevado, mas para o alargamento da força espiritual do indivíduo e elevação daquele pathos originário da moral nobre, o pathos da distância. Tomando por base a afirmação feita por Nietzsche em Ecce Homo, de que as três dissertações de Genealogia da Moral constituem "preliminares a uma transvaloração de todos os valores" 22 , não é descabido conceber mudanças substanciais nas obras de 1888 e levantar a hipótese de que uma superação da moral do ressentimento e da compaixão, nos termos de uma filosofia que pretende afirmar incondicionalmente todo o acontecimento, se dá por meio de uma nova moral cuja orientação prática é fornecida por "nossas" virtudes ${ }^{23}$ 


\section{Notas:}

${ }^{1}$ NIETZSCHE, F. Ecce Homo. Trad. Paulo César de Souza. São Paulo: Companhia das Letras, 2001, p. 70.

2 Tanto o Nascimento da tragédia, de 1871, quanto as Considerações Extemporâneas, de 1873/75, têm a elevação da cultura como fio condutor do empreendimento crítico de Nietzsche. Se na primeira obra publicada o vetor é a arte trágica como expressão de uma cultura superior e a defesa da música de Wagner como de arte suprema; as Considerações Extemporâneas fornecem um diagnóstico preciso da modernidade cultural da Alemanha tomando por base a completa dispersão dos objetivos da cultura, a ausência de um estilo próprio ao "espírito alemão" e a supervalorização da instrução (Gelehtheit). Em contraposição a isso, Nietzsche defende a formação (Bildung) como instância necessária a uma cultura elevada e toma para si dois exemplos claros a partir dos quais se pode articular, nesse momento, formação e cultivo: Schopenhauer como modelo de educador e Wagner como modelo de gênio. Em Humano, demasiado Humano, de 1878, o termo "höhere Cultur" aparece com bastante frequência, por exemplo, nos $\S \S 252,275,281,285$ e 439, quase sempre contraposto a uma cultura inferior. A partir daí, com frequência ainda maior, a noção de cultivo pode perfeitamente se articular à exigência de Nietzsche, cada vez mais constante, em pensar uma cultura elevada ou superior.

${ }^{3}$ NIETZSCHE, F. Além de Bem e Mal. Trad. Paulo César de Souza. São Paulo: Companhia das Letras, 1997, p. 63.

${ }^{4}$ Cf.: NIETZSCHE, F. Humano, Demasiado Humano II. Trad. Paulo César Souza. São Paulo: Companhia das Letras, 2008, p. 76: "Quem, em relação a povo tal como ele é, fala de uma necessidade profunda, de um insaciado anseio de arte, está mentindo ou delirando. Sejam honestos! - apenas em indivíduos de exceção há agora uma necessidade artística de alto estilo - porque a arte se encontra novamente em recuo, e as energias e esperanças humanas lançaram-se em outras coisas por algum tempo".

${ }^{5} \mathrm{O}$ termo Züchtung é uma constante nos fragmentos póstumos se referindo aos diversos sentidos recobertos pelo seu campo semântico. No plano geral do nosso trabalho pretendemos articular alguns sentidos dessa noção, exposta nos fragmentos, com o uso feito por Nietzsche nas obras publicadas a fim de dar maior visibilidade àquilo que consideramos ser o "projeto" do filósofo de pensar a elevação do homem sob a óptica da noção de cultivo. Acerca da recorrência do termo, cf., por exemplo, NIETZSCHE, F. Sämtliche Werke: Kritische Studienausgabe (KSA). Herausgegeben von G. Colli und M. Montinari. Berlin: De Gruyter, 1980, v. IX, pp. 508, 547, 577; Idem, v. X, pp. 286, 365, 480, 507; Idem, v. XI, pp. 98, 234, 260, 477, além de várias outras ocorrências. Nas obras publicadas as ocorrências do termo são pontuais. Por exemplo: (NIETZSCHE, F. Além de Bem e Mal, pp. 63, 65, 89,104, 150 e 177); (Idem, Crepúsculo dos Ídolos, p. 50). Em Ecce Homo, aparece no $\S 4$ sobre O nascimento da tragédia no sentido de Höherzüchtung [cultivo superior da humanidade] e em outras seções, de modo bastante sugestivo, correlacionado a termos próximos tais como: i) Selbstigkeit [cuidado de si], Selbstlosigkeit [ausência de si]; Selbsterhaltung [autopreservação], Selbstsucht [egoísmo], Selbstzucht [autodisciplina] (pp. 40, 48 e 67); ii) Erziehung [educação/formação], Selbst-Zucht [cultivo ou criação de si], Selbst-Vertheidigung [defesa de si] (p. 70); Selbstzucht [autodisciplina] (p. 76); Zucht (cultivo ou disciplina], Selbstsucht [egoísmo], Selbstlosigkeit [altruísmo] (p. 115).

${ }^{6}$ Os trabalhos de maior relevância acerca do tema têm sido realizados no Brasil por Wilson Frezatti Junior $(2001 ; 2006 ; 2010)$ e destacam justamente certa dificuldade na tradução do termo Züchtung na medida pode se aplicar a vários domínios. Segundo ele, "A tradução da palavra Züchtung é algo problemático devido aos sentidos que podem lhe ser atribuídos. O sentido comum de Züchtung é criação ou cultura (nos sentidos biológico - cultura de células -, agrário e botânico - cultura de milho). Zucht significa, comumente, criação, cultura (no sentido botânico), raça ou disciplina. Züchten significa criar ou cultivar (nos sentidos biológico e botânico)" (FREZATTI JUNIOR, W. "Os fragmentos póstumos sobre Darwin". (Tradução). In: Estudos Nietzsche, Curitiba, v. 1, n. 2, 2010, p. 416. Cf. também: Idem, “Sentidos do Darwinismo". In: Temas e Matizes, n. $15,1^{\circ}$ semestre de 2009, pp. 55-68; Idem, Nietzsche contra Darwin. São Paulo: Discurso Editorial/Editora Unijuí, 2001; Idem, A fisiologia de Nietzsche: superação da dualidade cultura/biologia. Ijuí: Editora Unijuí, 2006. De todo modo, sua interpretação destaca também o sentido que orienta o desenvolvimento da nossa questão, isto é, Züchtung no sentido de formação, disciplina e cultivo. Em sentido mais amplo, Patrick Wotling compreende o uso do termo feito por Nietzsche no registro da "élévation de la culture" (WOTLING, P. "La culture comme problème: la redetermination nietzschéenne du questionnment philosophique". In: NietzscheStudien, n. 37 (2008), p.2). De acordo com o intérprete, uma das maiores dificuldades, já antecipadas nas Considerações Extemporâneas, é "la possibilité d'agir sur les instincts et de définir les modalités de cette action. C'est là le probème de ce que Nietzsche nome dans un premier temps Erziehung, pour bientôt remplacer 
définitivement ce terme par celui de Züchtung: il est essentiel de remarquer que les termes de züchten, anzüchten, heranzüchten, Züchtung ou Zucht figurent parmi les plus employés du lexique de Nietzsche. Peu de commentateurs ont prêté attention à l'importance de cette problématique de la Züchtung chez Nietzsche, pourtant déterminante" (Idem, p. 36). Sobre esse tema, cf., ainda, WOTLING, P. Nietzsche et le problème de la civilization. Paris : PUF, 2012 e SCHANK, G. Rasse und Züchtung. Berlin/New York, 2000.

${ }^{7}$ Os trabalhos já citados de FREZZATI JUNIOR debateram de modo exaustivo alguns aspectos da crítica de Nietzsche a Darwin, mas também mostrou com igual consistência a influência sofrida por Nietzsche de várias tendências do naturalismo, tais como Haeckel, Carl Naegeli, W. Roux, W. H. Rolph e C. L. Rütmeyer. Essa mesma senda interpretativa foi percorrida, talvez de modo inaugural, por RICHTER, C. Nietzsche et les Théories biologiques contemporaines. Paris: Mercure de France, 1911, além de trabalhos mais recentes por STIEGLER, B. "Nietzsche lecteur de Darwin". Révue philosophique, n. 3, pp. 377-395, 1998 ; Idem, Nietzsche et la biologie. Paris: P. U. F, 2001.

${ }^{8}$ NIETZSCHE, F. Sämtliche Werke: Kritische Studienausgabe (KSA). Herausgegeben von G. Colli und M. Montinari, v. XII, p. 122. A referência a esse tipo de homem se multiplica nos fragmentos póstumos. Cf., por exemplo, Idem, v. XIII, p. 355: "O homem bom como tipo da décadence"; v. XIII, p. 471: "O homem bom. Ou: a hemiplegia da virtude"; 13, p. 608: "Problema: o que e propriamente o homem bom? Em primeiro lugar, o fraco: ele quer todos os homens fracos. Em segundo lugar, o limitado: ele quer todos os homens limitados. Em terceiro lugar, o animal de rebanho, o ser (das Wesen) sem direitos próprios: ele quer todos os homens como animais de rebanho".

${ }^{9}$ NIETZSCHE, F. Assim falou Zaratustra. Trad. Mario da Silva. Rio de Janeiro: Bertrand Brasil, p. 34.

${ }^{10}$ Essa relação entre uma cultura superior e o grande homem, exposta nos textos de juventude, se intensificará nos textos de 1888, de modo especial em Crepúsculo dos Idolos onde Nietzsche fornece seu conceito de gênio relacionando-o à cultura. Nesse momento o filósofo concede pouca importância ao "ambiente", à "época", ao “"espírito da época", à "opinião pública" na formação dos grandes homens, esses "materiais explosivos em que se acha acumulada uma tremenda energia" (NIETZSCHE, F. Crepúsculo dos Idolos. Trad. Paulo César Souza. São Paulo: Companhia das Letras, 2007, p. 93).

${ }^{11}$ NIETZSCHE, F. Sämtliche Werke. Kritische Studienausgabe (KSA), v. XII, p. 515.

${ }^{12}$ Idem, Aurora. Trad. Paulo César Souza. São Paulo: Companhia das Letras, 2000, p. 16. Essa noção foi bastante desenvolvida por GIACÓIA JUNIOR, O. "O grande experimento: sobre a oposição entre eticidade (Sittlichkeit) e autonomia em Nietzsche". In: Estudos Nietzsche, Curitiba, v. 1, n. 1, p. 73-128, jan./jun. 20101989.

${ }^{13}$ Idem, Aurora. Trad. Paulo César Souza. São Paulo: Companhia das Letras, 2004, p. 17.

${ }^{14}$ Idem, ibidem.

${ }^{15}$ Idem, Genealogia da Moral. Trad. Paulo César Souza. São Paulo: Companhia das Letras, 1998, p. 84.

${ }^{16}$ Esse termo, frequentemente usado por Nietzsche para se contrapor à ideia de "coletividade" ou dos valores relativos à moral de rebanho, pode ser destacado como operador importante na sua filosofia. De fato, se há uma prerrogativa do indivíduo no encaminhamento dos valores nobres, o mesmo é entendido por Nietzsche não no sentido da ideia moderna segundo a qual o indivíduo resguardaria em si alguma identidade ou substrato, mas no sentido de um pathos de diferenciação. Talvez a passagem mais esclarecedora seja um aforismo de Humano, demasiado Humano intitulado "A moral como autodivisão do homem" no qual Nietzsche afirma, no final do aforismo, que "Na moral o homem não trata a si mesmo como individuum, mas como dividuum" (NIETZSCHE, F. Humano, demasiado humano I, p. 59). Outras indicações acerca disso são dadas por Nietzsche ainda no volume I de Humano, demasiado Humano, p. 70, no aforismo 95: "Moral do indivíduo maduro"; Além de Bem e Mal, p. 178, onde vê o individuo como "o ponto inquietante e perigoso em que a vida maior, mais múltipla e mais abrangente vive além da velha moral", e no aforismo 2 da segunda dissertação de Genealogia da Moral, $\mathrm{p}$. 49, em que lança muito rapidamente a noção de um "individuo soberano" como "fruto mais maduro" do processo da moralidade do costume.

${ }^{17} \mathrm{Um}$ dos aspectos centrais que pretendemos acentuar é o caráter produtivo de determinadas virtudes, as virtudes nobres, no projeto nietzschiano de elevação do homem. Dentre as virtudes mais expressivas a serem cultivadas no sentido da autoelevação e que são tematizadas com frequência nos textos de Nietzsche podemos destacar, por 
exemplo: a solidão, "enquanto sublime pendor e ímpeto para o asseio, que percebe que no contato com as pessoas - em 'sociedade' - as coisas se dão inevitavelmente sujas” (Além de Bem e Mal, p. 191); o egoísmo, na medida em que "ele representa a linha de ascensão" do indivíduo e indica um "optimum de condições" da vida (Crepúsculo dos Idolos, p. 81); a formação (Bildung), com vistas a uma "Educação superior" cujo elemento essencial é "Aprender a pensar", ter "dedos para nuances" (Crepúsculo do Idolos, p. 61); a paciência no agir, isto é, "adiar o julgamento, aprender a rodear e cingir o caso individual de todos os lados" para alcançar a "primeira preparação para a espiritualidade: não reagir de imediato a um estímulo" (Crepúsculo dos Idolos, p. 60). Simplesmente "Porque nos consumiríamos muito rapidamente se reagíssemos, não reagimos mais, essa é a lógica" (Ecce Homo, p. 30); e a honestidade (Redlichkeit), "supondo que esta seja a nossa virtude, da qual não podemos escapar, nós, espíritos livres - bem, então vamos esmerá-la com toda a malicia e amor, e não cansar de nos 'perfeccionarmos' em nossa virtude, a única que nos resta" (Além de Bem e Mal, p. 132). Acerca dessa questão, cf., por exemplo, MARTON, S. "Silêncio, solidão". In: Cadernos Nietzsche, n. 9, 2000, pp. 79-105; OLIVEIRA, J. R. A Solidão como virtude moral em Nietzsche. Curitiba: Champagnat, 2010; BLONDEL, "La Patience de Nietzsche". In: Nietzsche-Studien 18 (1989), pp 432-439; TONGEREN, P von. "O filósofo como crítico e clínico da cultura". In: Estudos Nietzsche, Curitiba, v. 1, n. 2, 2010, p. 265-286.

${ }^{18}$ NIETZSCHE, F. O Anticristo. Trad. Paulo César de Souza. São Paulo: Companhia das Letras, 2006, p. 11.

${ }^{19}$ Idem, pp. 11-12.

${ }^{20}$ Idem, ibidem.

${ }^{21}$ Idem, p. 18.

${ }^{22}$ NIETZSCHE, F. Ecce Homo. Trad. Paulo César Souza. São Paulo: Companhia das Letras, 2001, p. 98.

${ }^{23}$ Talvez o texto mais emblemático de Nietzsche sobre o tema da virtude seja o capítulo VII de Além de Bem e Mal, "Nossas Virtudes". Esse texto abre uma discussão frontal com aquilo que se denomina "virtude" no domínio das ideias modernas as quais são cultivadas como "nossas", isto é, aquelas que dizem respeito ao homem moderno e são celebradas como o que de melhor aconteceu ao "melhoramento" da humanidade. "Nossas virtudes?", pergunta Nietzsche no inicio do aforismo 214. E responde: "É provável que também nós teremos ainda nossas virtudes". Como crítico das ideias modernas, Nietzsche projeta as "nossas" virtudes como "novas" virtudes, prerrogativa somente de "nós, europeus de amanhã" cuja tarefa será cultivar a partir de si mesmos, "como toda a nossa perigosa curiosidade, nossa multiplicidade e arte do travestimento, nossa branda e como que adocicada crueldade de espírito e de sentidos", aquelas virtudes, "se tivermos virtudes", "que aprenderem a se harmonizar com os nossos mais íntimos e autênticos pensadores, com as nossas mias ardentes necessidades: muito bem! Busquemo-las então em nossos labirintos!" (NIETZSCHE, F. Além de Bem e Mal, p. 123). 


\section{Referências bibliográficas:}

BLONDEL, E. “La patience de Nietzsche”. In: Nietzsche-Studien, 18 (1989), pp. 432-439.

BRUSOTI, M. "Ressentimento e vontade de nada". In: Cadernos Nietzsche, São Paulo, n. 8, 2000, pp. 3-34.

. "Reagir e não reagir: fisiologia e psicologia no Crepúsculo dos Ídolos”. In: Estudos Nietzsche, Curitiba, v. 1, n. 2, p. 373-388, jul./dez. 2010.

FREZATTI JUNIOR, W. “Os fragmentos póstumos sobre Darwin”. (Tradução). In: Estudos Nietzsche, Curitiba, v. 1, n. 2, p. 403-419, jul./dez., 2010.

"Sentidos do Darwinismo". In: Temas e Matizes, n. 15, 1 semestre de 2009, pp. 55-68.

. Nietzsche contra Darwin. São Paulo: Discurso Editorial/Editora Unijuí, 2001.

Editora Unijuí, 2006.

. A fisiologia de Nietzsche: superação da dualidade cultura/biologia. Ijuí:

GIACÓIA JÚNIOR, O. “A autossupressão como catástrofe da consciência moral”. In:

Estudos Nietzsche, Curitiba, v. 1, n. 1, p. 73-128, jan./jun. 2010.

. Nietzsche e Kant: uma disputa permanente a respeito de liberdade, autonomia e dever. São Paulo: Casa do Saber, 2012.

"O grande experimento: sobre a oposição entre eticidade (Sittlichkeit) e autonomia em Nietzsche”. In: Trans/Form/Ação, São Paulo, 12: 97 - 1 32, 1989.

HASSE, M-L. "Der Übermensch in also Sprach Zarathustra und im Zarathustra-Nachlass 1882-1885”. In: Nietzsche-Studien, 13 (1984), pp. 228-244.

MARTON, S. “Silêncio, solidão". In: Cadernos Nietzsche, n. 9, 2000, pp. 79-105.

NIETZSCHE, F. Sämtliche Werke: Kritische Studienausgabe (KSA). Giorgio Colli e Mazzino Montinari (Hg). Berlin: Walter de Gruyter, 1980.

. Obras incompletas. Tradução de Rubens R.T. Filho. São Paulo: Abril Cultural, 1979. (Col. Os Pensadores).

Assim falou Zaratustra: Um livro para todos e para ninguém. Trad. de Mário da Silva. Rio de Janeiro, Bertrand Brasil, 1995.

. O Nascimento da Tragédia ou Helenismo e Pessimismo. Trad., notas e posfácio de Jacob Guinsburg. São Paulo, Companhia das Letras, 1992.

. A Gaia Ciência. Trad., notas e posfácio de Paulo César de Souza. São Paulo: Companhia das Letras, 2001.

. Para Além de Bem e Mal. Trad., notas e posfácio de Paulo César de Souza.

ethic@- Florianópolis, Santa Catarina, Brasil, v.14, n.2, p.367 - 381, Dez. 2015. 
São Paulo: Companhia das Letras, 2000.

. A Genealogia da Moral: uma polêmica. Trad., notas e posfácio de Paulo César de Souza. São Paulo: Companhia das Letras, 2001.

. Aurora: reflexões sobre os preconceitos morais. Trad., notas e posfácio de Paulo César de Souza. São Paulo, Companhia das Letras, 2004.

. Humano, demasiado humano. Trad., notas e posfácio de Paulo César de Souza. São Paulo, Companhia das Letras, 2000.

. Ecce Homo. Trad., notas e posfácio de Paulo César de Souza. São Paulo, Companhia das Letras, 1995.

. O Anticristo. Trad., notas e posfácio de Paulo César de Souza. São Paulo, Companhia das Letras, 2007.

. Crepúsculo dos Ídolos. Trad., notas e posfácio de Paulo César de Souza.

São Paulo, Companhia das Letras, 2006.

OLIVEIRA, Jelson R. A solidão como virtude moral em Nietzsche. Curitiba: Champagnat, 2010.

PASCHOAL, A. E. “A palavra Übermensch nos escritos de Nietzsche”. In: Cadernos Nietzsche, n. 23, 2007, pp. 105-121.

. "Nossas virtudes: indicações para uma moral do futuro". In: Cadernos

Nietzsche, n. 12, 2002, pp. 53-70.

. Nietzsche e a Auto-Supressão da Moral. Ijuí: Editora Unijuí, 2009.

33, 2011, pp. 147-172.

. "Nietzsche e Dühring: ressentimento, vingança e justiça". In: Dissertatio, n.

RICHTER, Claire. Nietzsche et les Théories biologiques contemporaines. Paris: Mercure de France, 1911.

STIEGLER, B. “Nietzsche lecteur de Darwin”. Révue philosophique, n. 3, pp. 377-395, 1998. . Nietzsche et la biologie. Paris: P. U. F, 2001.

SCHANK, Gerd. Rasse und Züchtung bei Nietzsche. Berlin/New York, 2000.

SCHOPENHAUER, A. Sobre o fundamento da moral. Trad. de Maria. L. M. O. Cacciola. São Paulo: Martins Fontes, 2001.

TONGEREN, P. Von. "O filósofo como clínico da crítica da cultura”. In: Estudos Nietzsche, Curitiba, v. 1, n. 2, p. 265-286, jul./dez. 2010.

. A moral da crítica de Nietzsche à moral: estudo sobre "Para além de bem e mal”. Tradução de J. L. Viesenteiner. Curitiba: Champagnat, 2012.

VIESENTEINER, J. “'Cultivo’ e vivência (Erlebniss): premissas à construção da tarefa de 
'tornar-se o que se é' em Nietzsche”. In: Cadernos de Ética e Filosofia Política, n. 17, v. 2, 2010, pp. 203-227.

WOTLING, P. La philosophie de l'esprit libre. Introduction à Nietzsche. Paris: Flamarion, 2006.

"La culture comme problème : la redetermination nietzscheenne du questionnement philosophique”. In : Nietzsche-Studien, n. 37 (2008), pp. 1-50.

. Nietzsche et le problème de la civilization. Paris: P.U. F, 2012. 